\title{
VIVER E MORRER DE AMOR EM "O ANJO DAS DONZELAS"
}

\author{
Adriana da Costa Teles \\ Universidade de São Paulo / Fapesp \\ São Paulo, SP, Brasil
}

\begin{abstract}
Resumo: O presente artigo discute o conto "O anjo das donzelas" (1864), um dos primeiros que Machado de Assis publicou no Jornal das Famílias. Nossa reflexão pretende mostrar que Machado cria, nessa narrativa, uma curiosa discussão sobre o tipo de leitura a que as jovens da época estavam expostas e os efeitos equivocados que eventualmente poderiam ter em sua "formação moral", aspecto, aliás, bastante valorizado pelo veículo que fez circular o conto. Para o desenvolvimento de nossas considerações, partimos das duas citações que o autor faz da tragédia Romeu e Julieta, de Shakespeare, a nosso ver uma referência desencadeadora de várias possibilidades de significação dentro do contexto ficcional criado pelo escritor brasileiro no início de sua carreira.
\end{abstract}

Palavras-chave: Shakespeare; "O anjo das donzelas"; Romeu e Julieta; conto.

\section{Living and dying of love in "O anjo das donzelas"}

\begin{abstract}
This article discusses the short story "O anjo das donzelas" (1864), published by Machado de Assis in Jornal das Famílias at the beginning of his career. We intend to show that in this short story Machado creates a very interesting discussion of the kind of books young women were exposed at that time and the pernicious effects they could have on their "moral formation", something that was very important to the newspaper that published it. We start our discussion considering two quotes from Romeo and Juliet made on the short story. We believe that they create several possibilities of meaning in the ficcional context created by the Brazilian author at the beginning of his career.
\end{abstract}

Keywords: Shakespeare; "O anjo das donzelas"; Romeo and Juliet; short story.

"O anjo das donzelas" foi um dos primeiros contos que Machado de Assis publicou no Jornal das Famílias, periódico para o qual contribuiu de maneira quase ininterrupta de 1864 a 1878 . Veiculada nos meses de setembro e outubro de 1864 sob o pseudônimo de "Max", com o qual o autor assinou, também, "Oráculo" (1866), "O que são as moças" (1866), "O último dia de um poeta" (1866) e "Rui de Leão" (1872), "O anjo das donzelas" é uma das muitas narrativas do escritor que não recebeu atenção da crítica, permanecendo praticamente inexplorada pelos estudos que dão conta de sua produção nesse gênero. 
A trama pouco verossímil e aparentemente um tanto ingênua, de fato, não seduz em um primeiro momento, parecendo bastante adequada à literatura amena que o Jornal das Famílias visava oferecer para o seu público leitor, composto especialmente pelas mulheres. No entanto, essa história aparentemente descompromissada e, de certo modo, escrita ainda no princípio da carreira de Machado, iniciada, nesse gênero, em 1858, com "Três tesouros perdidos", é reveladora de posicionamentos importantes de nosso jovem escritor. É exatamente esse o ponto que conduz a nossa discussão. Retomemos o enredo da narrativa.

"O anjo das donzelas" narra a história de Cecília, jovem de quinze anos que, de tanto ler "tragédias de amor", forma um conceito bastante particular sobre o sentimento. Apesar de os romances afirmarem que o amor era algo divino, "ao mesmo tempo diziam-lhe também os livros que dos mais auspiciosos amores pode-se chegar aos mais lamentáveis desastres". ${ }^{1}$ Isso faz com que uma espécie de terror invada a donzela, que acaba por "determinar em seu espírito que nunca exporia o coração a tais catástrofes". ${ }^{2}$ Uma noite, depois de finalizar a leitura de um romance, a moça tem uma visão de algo que se identifica como sendo "o anjo das donzelas". Este lhe dá um anel e pede a ela para que nunca o tire do dedo; assim fazendo, estaria imune ao amor e, portanto, aos dissabores que pode provocar. Cecília aceita o pacto e procede exatamente como a imagem lhe dissera para fazer.

O tempo passa, Cecília amadurece, aos poucos, envelhece, os pais morrem, os pretendentes desistem das investidas e ela acaba por ir viver com uma irmã viúva, sem nunca ter se apaixonado. É quando retorna para a cidade o primo Tibúrcio, antigo apaixonado pela prima, que há muito anos - mais precisamente na noite em que Cecília tivera a visão - deixara o Rio de Janeiro. Os primos se reaproximam, Tibúrcio vai viver na casa das duas mulheres e certa noite observa que a prima nunca havia tirado do dedo o anel que ele pedira para que uma escrava lhe entregasse na noite de sua partida. Cecília, que não acredita no que ele lhe diz e revela, finalmente, sobre a visão que tivera, é instada a tirar o anel e comprovar a história do primo. Tirado o anel, lia-se dentro da aliança as iniciais de Tibúrcio. Cecília havia misturado as fortes impressões

\footnotetext{
${ }^{1}$ ASSIS, Machado de. Contos avulsos. Ed. R. Magalhães Júnior. Rio de Janeiro: Civilização Brasileira, 1956. p. 11.

${ }^{2}$ Idem, p. 12.
} 
deixadas pela leitura com seus sonhos e a aparição da escrava, passando, assim, a vida toda acreditando em algo que era fruto de sua imaginação.

A narrativa é muito curiosa e suscita várias questões para reflexão. Iniciamos nossas considerações chamando a atenção para a referência a Shakespeare que o conto apresenta. A tragédia Romeu e Julieta é citada em duas ocasiões do conto e, em princípio, a citação não surpreende o leitor, afinal, ambas as heroínas - Julieta e Cecília - são intrinsecamente ligadas à questão do amor. As citações são breves e aparentemente despretensiosas, utilizadas a título de ilustrar as fases da vida em que se encontra a protagonista da história. Na primeira citação, lemos:

Tem quinze anos. Quinze anos! É a idade das primeiras palpitações, a idade dos sonhos, a idade das ilusões amorosas, a idade de Julieta; é a flor, é a vida, e a esperança, o céu azul, o campo verde, o lago tranquilo, a aurora que rompe, a calhandra que canta, Romeu que desce a escada de seda, o último beijo que as brisas da manhã ouvem e levam, como um eco, ao céu. ${ }^{3}$

Na segunda citação, a referência à tragédia surge justamente para enfocar a passagem do tempo. Cecília já não tinha a idade de Julieta, mas se encontrava em uma fase mais madura de sua vida. É relevante observar que o narrador insiste em citar a peça, mesmo que seja para marcar uma diferença e não uma similaridade para com ela:

Cecília chegou aos trinta e três anos. Já não era a idade de Julieta, mas era uma idade ainda poética; poética neste sentido - que a mulher em chegando a ela, tendo já perdido as ilusões dos primeiros tempos, adquire outras mais sólidas, fundadas na observação. ${ }^{4}$

Quando observamos a referência à tragédia de Shakespeare de maneira mais próxima, no entanto, vemos que ela pode nos levar a uma relação mais ampla com a peça. Afinal, a leitura da narrativa nos leva a perceber que a atitude de Cecília se contrapõe à de Julieta. Na idade em que a heroína shakespeariana se entregou ao amor,

\footnotetext{
${ }^{3}$ Idem, p. 10.

${ }^{4}$ Idem, p. 19-20.
} 
com toda paixão trágica, Cecília se fechou inteiramente à experiência amorosa. ${ }^{5}$ Tratase de uma trajetória oposta, marcada pela entrega da heroína de Shakespeare, por um lado, e pela negação do amor por parte da personagem de Machado, por outro. A situação é curiosa. Analisemos.

A recusa em viver o amor por parte de Cecília relaciona-se diretamente às leituras que a jovem fazia, como observado anteriormente: "De há muito tempo que as tragédias do amor a que Cecília assistia nos livros causavam-lhe uma angustiosa impressão". ${ }^{6}$ Cecília, segundo o narrador, era inexperiente, não conhecia o amor, a não ser pelos livros, e, fora o colégio, nunca tinha ido a parte alguma. Desse modo, ao se deparar, em "muitas das páginas que lera [...] que o destino intervinha nos movimentos do coração humano", ${ }^{7}$ a jovem, "sem poder discernir o que teria de real ou de poético este juízo" ${ }^{8}$, tomou ao pé da letra o que lera, o que a deixou ainda mais apreensiva, sentindo-se à mercê de uma situação da qual, ao ser arrebatada, não tinha nenhum controle.

Cecília estava constantemente exposta a uma literatura que cultiva peripécias amorosas de toda sorte: "Tudo entra, bom ou mau, edificante ou corruptor, Paulo $e$ Virgínia ou Fanny", 9 o que teria provocado, nas palavras do narrador, um "estrago moral" na jovem, completado com a leitura da última novela, levando-a a "determinar em seu espírito que nunca exporia o coração a tais catástrofes". ${ }^{10}$ Desse modo, "o anjo das donzelas" caiu literalmente do céu, ao propor para ela uma saída frente à situação que tanto a amedrontava. No dia seguinte à suposta visão que a moça teve desse "ser", lemos:

[...] Cecília acordou com o anel no dedo e a consciência do que se passara na véspera. Nesse dia levantou-se da cama mais alegre que nunca. Tinha o coração leve e o espírito desassombrado. Tocara enfim

\footnotetext{
${ }^{5}$ É certo que a idade de Julieta, na peça de Shakespeare, era quatorze anos incompletos, enquanto Cecília contava quinze. No entanto, é, ainda, uma mesma fase da vida, a idade das "primeiras palpitações"; "dos sonhos"; "das ilusões amorosas"...

${ }^{6}$ ASSIS, Machado de. Contos avulsos, cit., p. 11.

${ }^{7}$ Idem, p. 12.

${ }^{8}$ Ibidem.

${ }^{9}$ Idem, p. 10-11.

${ }^{10}$ Idem, p. 12.
} 
o alvo que procurara: a indiferença para os amores, certeza de não estar exposta às catástrofes do coração... ${ }^{11}$

É certo que Cecília sente, ao longo dos anos, o peso de sua escolha, ou, melhor dizendo, da opção pelo pacto com o anjo. Ainda na juventude, "ela sentia um vácuo moral, uma solidão interior", ${ }^{12}$ que pareciam expressar a falta de algo vital para o seu ser: "Muitas vezes a aurora veio encontrá-la à janela, enlevada nas suas imaginações, sentindo um vago desejo de conversar com a natureza, embriagar-se no silêncio da noite". ${ }^{13}$ No entanto, a jovem não se permite reavaliar suas decisões, uma vez que acredita no sonho e nas vantagens que teria caso prosseguisse:

[...] as promessas feitas por ela [a visão] de uma bem-aventurança sem igual desenhavam na fantasia de Cecília um quadro vivo e esplêndido. Isto consolava a moça, e, sempre escrava dos juramentos, ela fazia honra sua em ficar pura do coração para subir à morada das donzelas libertadas do amor. ${ }^{14}$

Ao fazer o pacto com o anjo, Cecília tenta se proteger do amor da maneira como o mostram os livros que lê. No entanto, os romances a que estava exposta retratam o sentimento e o relacionamento amoroso a partir de uma visão romantizada e idealizada, fruto de uma determinada maneira de conceber o amor a dois naquele modelo de discurso literário. Incapaz de perceber os limites entre fantasia e realidade, a jovem, ao fazer o pacto com o anjo, incorre na mesma armadilha em que caíra, a de acreditar em uma fantasia. Trata-se de uma postura que é sustentada por sua inexperiência e ingenuidade e que a leva a abdicar de viver de maneira plena a sua vida.

Julieta morreu jovem, mas viveu com toda a força paixões da vida a que a personagem de Machado se fechou, desconhecendo-as e jamais vindo a vive-las. A proteção que Cecília encontrou no pacto estabelecido com o anjo a protegeu, acima de

\footnotetext{
${ }^{11}$ Idem, p. 14.

${ }^{12}$ Idem, p. 17.

${ }^{13}$ Ibidem.

${ }^{14}$ Ibidem.
} 
tudo, de uma existência mais autêntica e verdadeira, que lhe proporcionasse vivenciar seus sentimentos de maneira ampla e completa.

Em um primeiro momento, a leitura de "O anjo das donzelas" poderia levar o leitor a crer que, com o conto, Machado poderia estar estimulando as jovens a seguir o caminho que a sociedade de então indicava como sendo o mais correto para as mulheres: o matrimônio e a maternidade. Por essa perspectiva, Machado estaria, então, endossando uma determinada maneira de compreender o papel feminino naquele contexto: Cecília deveria ter se casado, afinal, o que a aguardou na velhice foi a solidão e o ridículo de ter acreditado a vida toda em uma fantasia. No entanto, não podemos esquecer que, se o destino da personagem de Machado deve-se, por um lado, a seu "espírito supersticioso", como assinala o narrador, por outro, encontra nas leituras que fazia o motivo decisivo de sua recusa ao amor. Há, assim, na narrativa, uma perspectiva crítica com relação a esse material.

O amor na literatura ocidental é retratado, ao longo da tradição, como algo repleto de sofrimento, o que a tragédia de Romeu e Julieta, ao ser citada duas vezes, se encarrega de lembrar ao leitor. Trata-se de uma abordagem que trabalha o sentimento como algo distante, que se realiza na morte, sendo impossível de se desenrolar de modo equilibrado no cotidiano dos amantes. Em $O$ amor $e$ o ocidente, um estudo clássico sobre o tema, o suíço Denis de Rougemont, ao revisitar o mito da paixão desde os primórdios, mostra, a partir da história de Tristão e Isolda, que o amor arrebatador é sinônimo de sentimento recíproco, mas infeliz, pois paixão é equivalente a sofrimento. ${ }^{15}$ Desse modo, nas grandes histórias de amor do ocidente, os amantes sempre encontram diversos e variados obstáculos, que é o que excita a obsessão passional. Quando os amantes finalmente superam os problemas e vão viver felizes para sempre, a história acaba. Rougemont argumenta que o que os amantes desejam é o próprio desejo; eles estão apaixonados por sua própria paixão. Nesse sentido, não podemos conceber uma Julieta que se casasse e vivesse feliz com Romeu. O casamento é monótono, pois nele não há obstáculo à realização erótica da paixão.

Desse modo, podemos compreender a presença da tragédia no conto de Machado como uma sugestão mais abrangente do que parece em princípio. Romeu $e$

${ }^{15}$ ROUGEMONT, D. Love in the western world. Princeton: Princeton University Press, 1983. 
Julieta é um exemplo muito presente no imaginário do leitor, mesmo aquele do século XIX, de um amor que se realizou na morte, que não conseguiu driblar as adversidades da vida em sociedade. Desse modo, mais do que uma alusão à entrega trágica ao amor por parte da heroína, a tragédia de Shakespeare parece constar na história como um exemplo limite de determinada concepção do amor, cultuada e cultivada pela literatura ocidental. É esse tipo de atitude para com o amor o que justifica, em última instância, a recusa de Cecília em viver o sentimento e justifica a sua trajetória.

No entanto, a partir dessa questão, colocada em cena pelo narrador, vemos a problematização de toda uma maneira de se lidar com o feminino naquela época. Analisemos a questão.

Cecília era uma jovem ingênua e inexperiente, que "do colégio saíra para casa e de casa não saíra para mais parte alguma". ${ }^{16}$ Alguém carente de qualquer tipo de experiência de vida e, portanto, capaz de absorver de maneira acrítica o que lia e de crer em um "anjo das donzelas", como o que supostamente lhe aparecera. A "pobre mocinha", como lhe chama o narrador, parece ser descrita como uma típica donzela da época, a devorar romances na solidão de sua "alcova virginal", alguém com quem a jovem que lê o Jornal das Famílias poderia facilmente se identificar ao ler no início do conto: "Lê, como disse, um livro, um romance, e apesar da hora adiantada, onze e meia, ela parece estar disposta a não dormir sem saber quem casou e quem morreu". ${ }^{17}$ No entanto, a continuação da cena permite irmos além. Leiamos:

Ao pé do leito, sobre a palhinha que forra o soalho, estende-se um pequeno tapete, cuja estampa representa duas rolas, de asas abertas, afagando-se com os biquinhos. Sobre esse tapete estão duas chinelinhas, de forma turca, forradas de seda cor de rosa, que o leitor jurará serem de um despojo de Cendrilon. São as chinelas de Cecília. Avalia-se já que o pé de Cecília deve ser um pé fantástico, imperceptível, impossível; e examinando bem pode-se até descobrir, entre duas pontas do lençol mal estendido, a ponta de um pé capaz de entusiasmar o meu amigo Ernesto C.... o maior admirador dos pés pequenos, depois de mim... e do leitor. ${ }^{18}$

\footnotetext{
${ }^{16}$ Idem, p. 11.

${ }^{17}$ Idem, p. 10.

${ }^{18}$ Ibidem.
} 
O narrador, como vimos, enfatiza o ato da leitura, estimulante a ponto de impedir interrupções por parte da moça, e descreve em minúcias alguns aspectos da decoração do quarto da jovem, em especial o tapete onde descansam os chinelos de Cecília. Os detalhes que fornece da decoração são reveladores da maneira com que a jovem pode ser compreendida.

Os dois pássaros que estampam o tapete "afagando-se com os biquinhos" sugerem o contato amoroso, que é retratado como algo delicado, quase comedido. Talvez o tipo de relacionamento que a "moça de família" era estimulada a ter na sua vida amorosa. As delicadas chinelinhas de seda cor de rosa, que lembram as da Cinderela, corroboram com essa imagem de delicadeza, distanciando a moça do mundo palpável, para inseri-la num mundo distante a que o adjetivo que qualifica as suas chinelas, "turca", remete. Cecília é uma donzela colocada em um ambiente essencialmente romantizado e idealizado.

No entanto, em meio a isso, o narrador chama a atenção do leitor para o pé de Cecília, cuja avaliação é de que "deve ser um pé fantástico, imperceptível, impossível" e convida o leitor para que descubra "entre duas pontas do lençol mal estendido, a ponta de um pé capaz de entusiasmar" a seu amigo Ernesto C..., a ele próprio e ao leitor. É importante observar que o narrador conversa com um leitor, e não com uma leitora. É relevante ressaltar, ainda, que o pé, principalmente o pé pequeno, como o descrito, era cultuado com devoção poética e revestido de sensualidade no século XIX. Como nos lembra Mary Del Priori, "pequenos, os pés tinham de ser finos, terminando em ponta; a ponta era a linha de mais alta tensão sensual"19. Desse modo, vemos que a cena mostra, por um lado, uma moça em atitude típica da época e com quem a leitora - público alvo daquele veículo - facilmente se identificaria; e, por outro lado, insere o elemento masculino no texto ao retratar a jovem como objeto de seu culto erótico. Desse modo, temos a caracterização de alguém protegido de vivências do mundo prático e sob o controle de determinadas pré-disposições socioculturais e objeto masculino.

O que talvez seja mais curioso de se observar é que essa narrativa tão crítica para com as leituras e as expectativas que as moças da época eram estimuladas a cultivar seja publicada em uma revista que tinha como objetivo atingir o público

${ }^{19}$ PRIORI, Mary Del. História do amor no Brasil. 3. ed. São Paulo: Contexto, 2012. p. 154. 
feminino, oferecendo a ele uma literatura amena e prezando pela moral e pelos costumes da época. Ora, Machado fez circular um ponto de vista crítico com relação ao que era consensual na época. Essa questão merece um olhar mais detido.

O Jornal das Famílias era um veículo essencialmente voltado para as mulheres. Como nos lembra Jean-Michel Massa, o periódico era "submetido à constante vigilância dos maridos e dos pais, que fiscalizavam as leituras de suas esposas e de suas filhas, devia além disso agradar às leitoras e alimentar as suas fantasias". ${ }^{20}$ Desse modo, o fato de o narrador conversar com o leitor - homem - no início da narrativa, deve ser motivo de atenção. Talvez o escritor tivesse em mente o fato de que o público masculino estava atento à publicação justamente no sentido de "fiscalizar" as leituras. Desse modo, Machado, que tão frequentemente dialogava com a sua "leitora", convida, aqui, esse leitor para que ouça a sua história e para que, junto com ele, se adentre na alcova da jovem donzela:

Cuidado, caro, leitor, vamos entrar na alcova de uma donzela.

A esta notícia o leitor estremece e hesita. É naturalmente um homem de bons costumes, acata as famílias e preza as leis do decoro público e privado. [...] Hesita e interroga a consciência se deve ou não continuar a ler as minhas páginas, e talvez resolva não prosseguir. [...]

Descanse, leitor, não verá neste episódio fantástico nada do que se não pode ver à luz pública. Eu também acato a família e respeito o decoro. Sou incapaz de cometer uma ação má, que tanto importa delinear uma cena ou aplicar uma teoria contra a qual proteste a moralidade.

Tranquilize-se, dê-me o seu braço, e atravessemos, pé ante pé, a soleira da alcova da donzela Cecília. ${ }^{21}$

A cena acima nos leva a perceber que o narrador, de maneira um tanto irônica, brinca com o leitor a pretexto de ganhar a sua credibilidade e confiança. Apesar da invasão da intimidade de Cecília, não é necessário se assustar; ele também preza pelo decoro e pelos bons costumes. O objetivo do narrador é o de convidar o leitor para que observe uma jovem donzela em um espaço íntimo. Lembramos que, no século XIX, as

\footnotetext{
${ }^{20}$ MASSA, Jean-Michel. A juventude de Machado de Assis. Rio de Janeiro: Civilização Brasileira, 1971. p. 541.

${ }^{21}$ ASSIS, Machado de. Contos avulsos, cit., p. 9.
} 
alcovas eram o lugar da individualidade, dando privacidade aos sentimentos $\mathrm{e}$ possibilitando que aflorassem, em oposição às salas de jantar e aos salões, com suas regras e máscaras sociais. É possível, assim, que, adentrando nesse ambiente, se observe Cecília em toda honestidade de seus sentimentos e da maneira mais pura de seu ser. É assim que o narrador quer o leitor veja Cecília. Antes de prosseguirmos nossa reflexão, convém observar que o recurso de construção dessa primeira cena do conto resvala no cinematográfico; o leitor é conduzido "pé ante pé" ao cenário e à protagonista, como que por meio de uma câmera. O dado é muito interessante, pois parece frisar a construção do caráter ficcional da narrativa.

Esse preparo do que se verá é corroborado pela descrição detalhada e pela explicação que nos fornece o narrador acerca do nome da personagem. Este aparentemente ilustra uma determinada impressão que o narrador quer dar dela. Leiamos:

Há certos nomes que só assentam em certas criaturas, e que quando ouvimos pronunciá-los como pertencentes a pessoas que não conhecemos, logo atribuímos a estas os dons físicos e morais que julgamos inseparáveis daqueles. Este é um desses nomes. Veja o leitor se a moça que ali se acha no leito, com o corpo meio inclinado, um braço nu escapando-se do alvo lençol e tendo na extremidade uma mão fina e comprida, os cabelos negros, esparsos, fazendo contraste com a brancura da fronha, os olhos meio cerrados lendo as últimas páginas de um livro, veja se aquela criatura pode ter outro nome, e se aquele nome pode estar em outra criatura. ${ }^{22}$

Colocado diante da cena e convidado a ouvir a história, o leitor poderá perceber que a personagem observada parece uma típica donzela da época. Seu nome, segundo o narrador, tão adequado à figura, retoma, em um primeiro momento, a delicadeza e a pureza das heroínas românticas. Aliás, a descrição da cena é perfeitamente adequada a um romance desse teor. No entanto, o nome Cecília, proveniente do latim, retoma o termo caecus, cujo significado é "cego". Desse modo, para além da caracterização quase cinematográfica da jovem, com toda uma carga romantizada, ela é ironicamente nomeada por aquilo que será uma marca de sua

${ }^{22}$ Idem, p. 10-11. 
trajetória. Há, assim, uma ironia para com o leitor, que poderá ser logrado, caso não consiga fazer uma leitura crítica do que vê e se deixe seduzir pelas aparências do que assiste. Cecília, enquanto donzela romântica e ingênua, como é caracterizada, é, antes de qualquer coisa, uma cega para com os fatos da vida e do mundo, reclusa que está em sua alcova a fazer leituras que a conduzem a uma visão romantizada da vida. O convite ao leitor para que assista a essa cena e ouça essa história parece ser, assim, estratégico. Apesar de o narrador afirmar que não se verá no conto nada "que não pode ver à luz pública", a narrativa apresenta uma maneira bastante peculiar de conceber a jovem donzela da época e as leituras que praticava e que era estimulada a fazer. É a refletir sobre isso que o leitor é convidado.

Percebe-se, assim, que o conteúdo da narrativa acaba por questionar o tratamento que jovens donzelas recebiam tanto da sociedade do tempo, da qual o homem (leitor) era o patriarca, quanto, em certo sentido, da própria revista, cujo conteúdo tinha uma perspectiva normativa, com função moral e pedagógica. É interessante retomar, aqui, as reflexões de Maria Helena Câmara Bastos, quando analisa o Jornal das Famílias. Para a pesquisadora, apesar de a revista ser dirigida ao público feminino, a contribuição era em sua esmagadora maioria feita pelos homens. Após analisar cuidadosamente dados referentes a escritores e escritoras que contribuíam com a revista, ela afirma, "o periódico, mesmo destinado às mulheres, é dirigido pelos homens, que tomam a si a função de serem os autores das mulheres, de interpretar e dar sentido ao feminino, tratando-as de forma estereotipada [...]". ${ }^{23}$ Nesse conto, Machado, em atitude um pouco diferente com relação ao padrão da época e da revista, se dirige àquele que é o "autor" da mulher, seja dentro do periódico - enquanto escritor, colaborador ou editor - seja ao pai de família, que está atento às leituras das mulheres da casa. Vemos que o jovem escritor, então com cerca de 25 anos, não se esquiva de mostrar como lê a situação que vê a seu redor, fazendo circular uma determinada leitura questionadora de como a moça daquela época era formada e estimulada a ser.

Surge, assim, uma crítica mais ampla a um tipo de formação feminina que privilegiava a inexperiência e a ingenuidade, formando mulheres despreparadas para uma vivência mais abrangente e completa. Cecília preencheu uma fantasia com outra,

\footnotetext{
23 BASTOS, M.H.C. Leituras das Famílias Brasileiras no Século XIX: o Jornal das Famílias (1863-
} 1878). Revista Portuguesa de Educação. Braga: Universidade do Minho, 2002. p. 182. 
acreditando cegamente que o amor é da maneira que o fantasiam os livros românticos e, posteriormente, em fantasias, como a de anjos protetores.

Retomando a questão do amor enquanto dor e sofrimento que a literatura ocidental geralmente veicula, vemos que o conto de Machado ensaia dissolver essa imagem, propondo novas maneiras de se lidar com o sentimento. Um poeta romântico, pretendente de Cecília, ainda na juventude da moça, não suportou a recusa da donzela e se suicidou, mas aqueles que não compartilham de excessos romanescos administram os dissabores, seguem a vida sem dramas ou tragédias. O resultado de crenças e ilusões ingênuas é o ridículo, a que Cecília percebe que se expôs a vida toda.

"O anjo das donzelas" talvez seja uma daquelas narrativas que Lúcia Miguel Pereira tinha em mente quando afirmou que as histórias de Machado dos primeiros tempos compunham uma "literatura amena de pura fantasia, sem nenhum fundamento na realidade". ${ }^{24}$ De fato, o conto carrega, sim, o peso da inexperiência de seu autor. Longo demais, certamente dentro dos padrões de extensão requeridos pela revista, o conto contém incongruências: a crença de que houve de fato um pacto com o "anjo das donzelas" é suficiente para se evitar o amor? O amor seria, assim, um sentimento controlável por fortes determinações pessoais? O excesso de ingenuidade de Cecília não torna a trama inverossímil e pouco convincente? Seguramente essas e outras questões apontam para um texto que é passível de crítica, mas essas não são suficientes para desmerecer o conto. Nele, vemos, além dos primórdios de um processo intertextual que o escritor traça com as peças de Shakespeare, e que estaria presente ao longo de praticamente toda a sua carreira, que o jovem escritor faz circular ideias muitos próprias, seja no âmbito do estético ou do social, procurando um espaço para romper com concepções engessadas e facilmente aceitas, dialogando de maneira crítica com tudo e todos.

${ }^{24}$ PEREIRA, Lúcia Miguel. Machado de Assis. 5. ed. São Paulo: José Olympio, 1955. p. 135. 


\section{Referências:}

ASSIS, Machado de. Contos avulsos. Ed. R. Magalhães Júnior. Rio de Janeiro: Civilização brasileira, 1956.

BASTOS, M.H.C. Leituras das Famílias Brasileiras no Século XIX: o Jornal das Famílias (1863-1878). Revista Portuguesa de Educação. Braga: Universidade do Minho, 2002. p. 169-214.

MASSA, J. M. A juventude de Machado de Assis. Rio de Janeiro: Civilização Brasileira, 1971.

PEREIRA, Lúcia Miguel. Machado de Assis. 5. ed. São Paulo: José Olympio, 1955.

PRIORI, M. D. História do amor no Brasil. 3. ed. São Paulo: Contexto, 2012.

ROUGEMONT, D. Love in the western world. Princeton: Princeton University Press, 1983.

Adriana da Costa Teles realizou pesquisa de pós-doutorado em Teoria da Literatura na Universidade de São Paulo. É autora do livro O labirinto enunciativo em Memorial de Aires (Annablume, 2009) e de diversos artigos publicados no Brasil e no exterior. Interesses atuais de pesquisa envolvem a presença de Shakespeare na obra de Machado de Assis. Atualmente realiza segundo estágio de pós-doutorado na Universidade de São Paulo, com bolsa Fapesp, desenvolvendo o projeto: "Romeu e Julieta nos contos de Machado de Assis: uma poética do amor e do desengano". E-mail: <driteles@ig.com.br>.

Recebido: 13.09.2013

Aprovado: 20.11.2013 